\title{
A case of cohesinopathy with a novel de-novo SMC1A splice site mutation
}

Hansen, Jörg ; Mohr, Julia ; Bürki, Sarah ; Lemke, Johannes R

DOI: https://doi.org/10.1097/MCD.0b013e3283645439

Posted at the Zurich Open Repository and Archive, University of Zurich

ZORA URL: https://doi.org/10.5167/uzh-168113

Journal Article

Published Version

Originally published at:

Hansen, Jörg; Mohr, Julia; Bürki, Sarah; Lemke, Johannes R (2013). A case of cohesinopathy with a novel de-novo SMC1A splice site mutation. Clinical Dysmorphology, 22(4):143-145.

DOI: https://doi.org/10.1097/MCD.0b013e3283645439 


\section{A case of cohesinopathy with a novel de-novo SMC1A splice site mutation Jörg Hansen ${ }^{a}$, Julia Mohr ${ }^{c}$, Sarah Bürki ${ }^{b}$ and Johannes R. Lemke ${ }^{a}$}

Clinical Dysmorphology 2013, 22:143-145

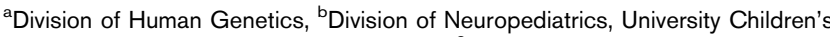
Hospital, Inselspital, Bern, Switzerland and ${ }^{\circ} \mathrm{CeGaT} \mathrm{GmbH}$, Tübingen, Germany

\author{
List of key features \\ Developmental delay \\ Microcephaly \\ Dysmorphism \\ Congenital diaphragmatic hernia \\ Generalized epilepsy \\ Unilateral camptodactyly of fifth finger
}

\section{Short clinical summary}

The patient's mother reported a twin pregnancy with missed abortion of one of the twins around the sixth week of gestation. Shortly before birth, a prenatal ultrasound revealed a diaphragmatic hernia and microcephaly in the remaining twin. The female patient was born at the 41st week of gestation. Her birth weight was $2720 \mathrm{~g}$ (P10) and her body length was $50 \mathrm{~cm}$ (P50). Postpartal investigation revealed congenital hip dysplasia. The diaphragmatic hernia was operated upon at the age of 2 days. The body length and weight consistently developed close to the 10th centile, whereas the head circumference was constantly below the third. The developmental milestones were delayed (free walking at 18 months and first words at $2 \frac{1}{2}$ years). The first epileptic seizures occurred at the age of 3 months. The girl had generalized tonic-clonic seizures, occasionally occurring in impressive clusters lasting $24-48 \mathrm{~h}$ as well as clusters of seizures with secondary generalization. The electroencephalography showed nonspecific monomorphic generalized slow-wave activity with rare spikes. The parents never observed febrile seizures but reported seizures in connection with a sinking body temperature after febrile infections. Genetic analysis revealed a normal female karyotype of 46,XX and normal array comparative genomic hybridization results.

On examination at the age of 11 years, the patient measured $135 \mathrm{~cm}$ and weighed $31.5 \mathrm{~kg}$ (both P10-P25) with a head circumference of $49.5 \mathrm{~cm}(\mathrm{P} 1,-2.5 \mathrm{SD})$. The dysmorphic features included a round face with arched eyebrows, a short nose, upslanting palpebral fissures, a smoothed philtrum, mild retrognathia, crowded teeth, a flattened midface, clinodactyly of the fifth fingers and camptodactyly of the fifth finger on the right (Fig. 1a-c). There were no flexion deficits of the elbows.

\author{
Correspondence to Johannes R. Lemke, MD, Division of Human Genetics, \\ University Children's Hospital, Inselspital, CH-3010 Bern, Switzerland \\ Tel: +41316329446; fax: +4131632 9484; e-mail: johannes.lemke@insel.ch
}

Received 21 January 2013 Accepted 17 June 2013

The patient was the second daughter of healthy and nonconsanguineous parents of Swiss origin. The family history was unremarkable, apart from two spontaneous abortions (at approximately the 12th and sixth weeks of gestation) before the patient's healthy elder sister.

\section{Investigations}

DNA samples of the patient and both parents were isolated from peripheral blood leucocytes using routine procedures. Molecular genetic analysis of 323 genes involved in epileptogenesis using a targeted next generation sequencing (NGS) approach (epilepsy panel version 2) was performed as recently described (Lemke et al., 2012). Validation of the patient's mutation and analysis of its parental origin was performed by classical Sanger sequencing. We further evaluated the effect of the detected mutation by different in-silico prediction tools (MutationTaster, Human Splicing Finder) (Desmet et al., 2009; Adzhubei et al., 2010; Schwarz et al., 2010).

\section{Results}

Within the 323 genes investigated by the NGS epilepsy panel, we revealed 101 variants with a global minor allele frequency of less than 5\%. We disregarded the following: (a) variants within the $5^{\prime}$ or $3^{\prime}$ untranslated region, (b) intronic variants more than $\pm 20 \mathrm{bp}$ outside of the common splice sites, (c) synonymous exonic variants more than \pm 2 bp outside of the common splice sites and (d) variants that were evaluated as being most probably false positives/technical artefacts (e.g. variants present only in forward or reverse reads, those at adjacent positions and those present in $<20 \%$ of reads).

Among the remaining 12 variants, four were novel to dbSNP 135 (http://wwwr.ncbinlm.nih.gov/projects/SNP/) (Table 1). Ten of these 12 variants were unlikely to be causative because of two or more of the following reasons: (a) there was only one heterozygous variant within a recessive gene, (b) the gene was not suggestive of the patient's phenotype and (c) the reference sequence presented with the minor allele.

Two variants in SCN9A and SMC1A were novel to dbSNP 135 and the exome variant server (Seattle, Washington, USA; evs.gs.washington.edu/EVS/) and remained with unclear significance. 
Fig. 1
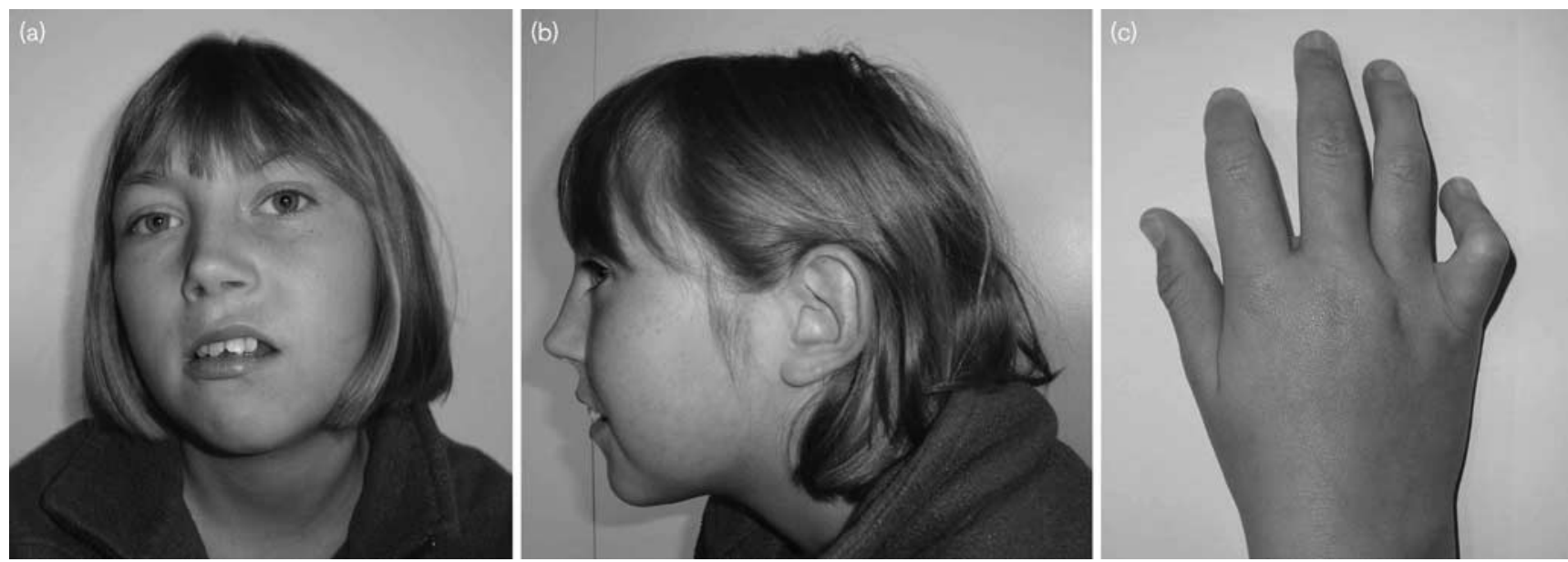

(a) The patient has a round face, arched eyebrows, short nose, upslanting palpebral fissures, smoothed philtrum and crowded teeth; (b) mild retrognathia and a flattened midface and (c) clinodactyly of the fifth fingers and camptodactyly of the fifth finger on the right.

Table 1 List of detected variants

\begin{tabular}{|c|c|c|c|c|c|c|c|}
\hline Gene & Mutation & $\begin{array}{l}\text { Change of amino } \\
\text { acid }\end{array}$ & Functional class & $\begin{array}{l}\text { ID dbSNP } \\
135\end{array}$ & Associated disorder & Inheritance & Evaluation \\
\hline$A L D H 4 A 1$ & c. $678+3 G>A$ & NA & Intronic & rs138788183 & Hyperprolinaemia type II & AR & $\begin{array}{l}\text { AF } 0.6 \% \\
\text { No second mutation }\end{array}$ \\
\hline ALG12 & c. $768+17 \mathrm{G}>\mathrm{A}$ & NA & Intronic & rs145358718 & CDG1G & AR & No second mutation \\
\hline ALG6 & $\mathrm{C} 167+19 \mathrm{G}>\mathrm{C}$ & NA & Intronic & Novel & CDG1C & AR & No second mutation \\
\hline ASPM & c. $7737 \mathrm{~T}>\mathrm{C}$ & p.Y2494H & NS, coding & rs964201 & Microcephaly & AR & $\begin{array}{l}\text { Reference has minor } \\
\text { allele } \\
\text { No second mutation }\end{array}$ \\
\hline$E I F 2 B 1$ & c. $615 G>C$ & p.D158H & NS, coding & Novel & $\begin{array}{l}\text { Leucoencephalopathy with vanishing } \\
\text { white matter }\end{array}$ & AR & No second mutation \\
\hline EIF2B4 & c. $704 \mathrm{G}>\mathrm{A}$ & p.A235T & NS, coding & rs41288829 & $\begin{array}{l}\text { Leucoencephalopathy with vanishing } \\
\text { white matter }\end{array}$ & AR & $\begin{array}{l}\mathrm{AF}>3 \% \\
\text { No second mutation }\end{array}$ \\
\hline LAMA2 & c. $9200-15 C>A$ & NA & Intronic & rs55776770 & Merosin-deficient muscular dystrophy & AR & No second mutation \\
\hline$N R X N 1$ & c. $2745 \mathrm{C}>\mathrm{T}$ & p.P469S & NS, coding & rs78540316 & Pitt-Hopkins-like syndrome & AR & No second mutation \\
\hline PAX6 & c. $129+9 \mathrm{G}>\mathrm{A}$ & NA & Intronic & rs56139994 & Aniridia & $\mathrm{AR} /(\mathrm{AD})$ & $\begin{array}{l}\text { AF } 4.2 \% \\
\text { No second mutation }\end{array}$ \\
\hline RELN & c. $5268 \mathrm{C}>\mathrm{G}$ & p.P1703R & NS, coding & rs2229860 & Lissencephaly & AR & $\begin{array}{l}\text { AF } 1.7 \% \\
\text { No second mutation }\end{array}$ \\
\hline SCN9A & c. $1154 \mathrm{~T}>\mathrm{G}$ & p.V385G & NS, coding & Novel & $\begin{array}{l}\text { Generalized epilepsy with febrile seizures } \\
\text { plus }\end{array}$ & AD & Inherited paternally \\
\hline SMC1A & c. $1731 \mathrm{G}>\mathrm{A}$ & p.E577E & $\begin{array}{l}\text { S, coding, splice } \\
\text { site }\end{array}$ & Novel & Cornelia de Lange syndrome-2 & $X D$ & De novo \\
\hline
\end{tabular}

All 12 detected variants within the targeted 323 genes that remained after the filtering procedure, 10 of which were unlikely to be causative are shown. Of the remaining two variants, only SCM1A c.1731G > A appeared to be of de-novo origin and compatible with the girl's phenotype.

$A D$, autosomal dominant; AF, allele frequency; AR, autosomal recessive; CDG, congenital disorder of glycosylation; NA, not applicable; NS, nonsynonymous; $\mathrm{S}$, synonymous; XD, X-linked dominant.

Finally, the synonymous heterozygous splice variant SMC1A c. $1731 \mathrm{G}>\mathrm{A} / \mathrm{p} . \mathrm{E} 577 \mathrm{E}$ at the last position of exon 10 was proven to be of de-novo origin and predicted to cause a loss of the donor splice site motif. The heterozygous variant SCN9A c.1154T > G/p.V385G within exon 9 was predicted to be pathogenic as well but was inherited from the healthy father. Thus, we evaluated the SCN9A variant as a presumably rare polymorphism and the de-novo SMC1A variant as the most likely causative, leading to the diagnosis of cohesinopathy in our patient. Because of the lack of further consent, additional mRNA studies could not be performed to further support this conclusion.

\section{Discussion}

Retrospectively, the girl's symptoms and facial gestalt are compatible with mild Cornelia de Lange syndrome (CdLS). However, we did not consider this diagnosis initially, and thus did not primarily commence with direct genetic testing of SMC1A. Unfortunately, this is a frequent situation in clinical genetics, as symptoms and features of a patient only rarely allow a concise and correct diagnosis and often require considerable syndromatological knowledge. Hence, targeted NGS can release clinicians from the prerequisite of a precise clinical diagnosis before genetic testing. 
Most known SMC1A patients have been detected because of their CdLS/CdLS-like phenotypes (Deardorff et al., 2007). However, several patients lacking classical or suggestive phenotypic features (Deardorff et al., 2007) prove that the spectrum of SMC1A mutations might go beyond the known CdLS-like phenotype. This is supported by the case of a recently described nonsyndromic, autistic patient carrying a SMC3 mutation (Sanders et al., 2012). Thus, a direct clinical diagnosis can be challenging and the broader term 'cohesinopathy' might be more adequate for this phenotypic spectrum than is CdLS.

The mutation c. $1731 \mathrm{G}>\mathrm{A} / \mathrm{p} . \mathrm{E} 577 \mathrm{E}$ in our patient expands the mutational spectrum of SMC1A to splice site mutations and also represents the first exonic synonymous splice site mutation observed in any human cohesinopathy.

The detected variant SCN9A p.V385G remains of unknown significance. Because of paternal inheritance, it is unlikely to be causative of the girl's phenotype but might still modify her generalized epilepsy (Singh et al., 2009).

Congenital diaphragmatic hernias have been described occasionally in patients with 'classic' CdLS because of NIPBL mutations (Fryns, 1987). However, Deardorff et al. (2007) reported no diaphragmatic hernias nor other major structural abnormalities in SMC1A (and SMC3) patients. Our observation reveals that diaphragmatic hernias are also part of the milder (non-NIPBL) cohesinopathies.

Finally, we demonstrate how NGS panel diagnostics significantly facilitate mutation detection. Screening of larger cohorts with less specific phenotypes might help reveal the true phenotypic spectrum of many conditions, not only of human cohesinopathies or epilepsies. As shown in several cases, it will dramatically expand our understanding of the genotype-phenotype correlations of known (and yet unknown) disease-causing genes (Kousi et al., 2012; Lemke et al., 2012).

\section{Acknowledgements}

The authors thank the patient and her parents for their support.

\section{Conflicts of interest}

There are no conflicts of interest.

\section{References}

Adzhubei IA, Schmidt S, Peshkin L, Ramensky VE, Gerasimova A, Bork P, et al. (2010). A method and server for predicting damaging missense mutations. Nat Methods 7:248-249.

Deardorff MA, Kaur M, Yaeger D, Rampuria A, Korolev S, Pie J, et al. (2007). Mutations in cohesin complex members SMC3 and SMC1A cause a mild variant of Cornelia de Lange syndrome with predominant mental retardation. Am J Hum Genet 80:485-494.

Desmet FO, Hamroun D, Lalande M, Collod-Beroud G, Claustres M, Beroud C (2009). Human Splicing Finder: an online bioinformatics tool to predict splicing signals. Nucleic Acids Res 37:e67.

Fryns JP (1987). Posterolateral diaphragmatic hernia and Brachmann-de-Lange syndrome. Arch Fr Pediatr 44:474.

Kousi M, Anttila V, Schulz A, Calafato S, Jakkula E, Riesch E, et al. (2012). Novel mutations consolidate KCTD7 as a progressive myoclonus epilepsy gene. J Med Genet 49:391-399.

Lemke JR, Riesch E, Scheurenbrand T, Schubach M, Wilhelm C, Steiner I, et al. (2012). Targeted next generation sequencing as a diagnostic tool in epileptic disorders. Epilepsia 53:1387-1398.

Sanders SJ, Murtha MT, Gupta AR, Murdoch JD, Raubeson MJ, Willsey AJ, et al. (2012). De novo mutations revealed by whole-exome sequencing are strongly associated with autism. Nature 485:237-241.

Schwarz JM, Rodelsperger C, Schuelke M, Seelow D (2010). MutationTaster evaluates disease-causing potential of sequence alterations. Nat Methods 7:575-576.

Singh NA, Pappas C, Dahle EJ, Claes LR, Pruess TH, De Jonghe P, et al. (2009). A role of $\mathrm{SCN} 9 \mathrm{~A}$ in human epilepsies, as a cause of febrile seizures and as a potential modifier of Dravet syndrome. PLoS Genet 5:e1000649. 